\title{
Cytokine pattern in very early rheumatoid arthritis favours B cell activation and survival
}

\author{
R A Moura ${ }^{1 \dagger}$, R Cascão ${ }^{1 \dagger}$, I Perpétuo ${ }^{1}$, H Canhão ${ }^{1,2}$, E Vieira de Sousa ${ }^{1,2}$, A F Mourão ${ }^{1,3}$, A M Rodrigues ${ }^{1,2}$, \\ J Polido-Pereira ${ }^{1,2}$, M Viana Queiroz ${ }^{2}$, H S Rosário ${ }^{4}$, M M Souto-Carneiro ${ }^{5}$, L Graca ${ }^{6,7^{*}}$, J E Fonseca ${ }^{1,2^{*}}$ \\ From 5th European Workshop on Immune-Mediated Inflammatory Diseases \\ Sitges-Barcelona, Spain. 1-3 December 2010
}

\section{Introduction}

B cells play an important role in the perpetuation of rheumatoid arthritis (RA), particularly as autoantibody producing cells. The immune complexes that further develop deposit in the joints and aggravate the inflammatory process. However, B cells contribution in the very early stage of the disease remains unknown.

\section{Aim}

To determine the concentration of cytokines potentially relevant for $B$ cell activation in serum from very early polyarthritis patients, with less than 6 weeks of disease duration, who latter on evolved into RA (VERA).

\section{Patients and methods}

APRIL, BAFF and IL-21 levels were measured by ELISA in the serum of VERA, other very early arthritis (VEA), established RA patients and controls. Synovial fluid (SF) samples of established RA were also analyzed.

\section{Results}

VERA patients have higher levels of APRIL and BAFF as compared to VEA, established RA and controls. Furthermore, APRIL and BAFF levels are also significantly elevated in RA-SF when compared to serum.

\section{Conclusions}

The increased levels of APRIL and BAFF in VERA patients suggests that $B$ cell activation and the development of autoreactive $B$ cell responses might be crucial in early phases of RA. Therefore, APRIL and BAFF could be promising targets for therapy in the early phase of RA.

\section{Author details}

${ }^{1}$ Rheumatology Research Unit, Instituto de Medicina Molecular, Faculdade de Medicina da Universidade de Lisboa, Lisbon, Portugal. ${ }^{2}$ Rheumatology Dept., Centro Hospitalar de Lisboa Norte, EPE, Hospital de Santa Maria, Lisbon, Portugal. ${ }^{3}$ Rheumatology Dept., Centro Hospitalar de Lisboa Ocidental, EPE, Hospital Egas Moniz, Lisbon, Portugal. ${ }^{4}$ Microvascular Biology and Inflammation Unit, Instituto de Medicina Molecular, Faculdade de Medicina da Universidade de Lisboa, Lisbon, Portugal. ${ }^{5}$ Center for Neurosciences and Cell Biology, Autoimmunity Group, Coimbra, Portugal. ${ }^{6}$ Cellular Immunology Unit, Instituto de Medicina Molecular, Faculdade de Medicina da Universidade de Lisboa, Lisbon, Portugal. 'Instituto Gulbenkian de Ciência, Oeiras, Portugal.

Published: 25 November 2010

\section{doi:10.1186/1479-5876-8-S1-P33}

Cite this article as: Moura et al:: Cytokine pattern in very early rheumatoid arthritis favours B cell activation and survival. Journal of Translational Medicine 2010 8(Suppl 1):P33.

\footnotetext{
† Contributed equally

'Rheumatology Research Unit, Instituto de Medicina Molecular, Faculdade de Medicina da Universidade de Lisboa, Lisbon, Portugal

${ }^{6}$ Cellular Immunology Unit, Instituto de Medicina Molecular, Faculdade de

Medicina da Universidade de Lisboa, Lisbon, Portugal

Full list of author information is available at the end of the article
} 